\title{
1. The Design Approach revisited: background and meaning
}

\section{Annette Kur and Marianne Levin}

\section{INTRODUCTION}

\section{Before Harmonization: An Exemplary Case Scenario}

In 1977, one Mr. Siegel filed a design patent application with the US Patent Office for a ladies' handbag. The design patent was then assigned to the firm Amba Marketing Systems, and the handbag was sold on the US market through the mail-order firm Ambassador. After a while the design was considered outdated, and the handbag was removed from Ambassador's assortment of deliverable items. However, although this occurred in times pre-dating the internet, globalization was on the move, and in this case it meant that identical or similar handbags continued to be manufactured in Taiwan, whence they made their way to Europe. The design was considered appealing by a number of firms, thereunder Nancy Kean Gifts (NKG) in Den Haag. In order to secure exclusive marketing rights in the Netherlands, they filed and obtained a design registration from the Benelux Trade Mark and Design Office. Based on that right they sued Keurkoop, a Dutch mail-order firm selling similar bags that were likewise imported from Taiwan. As turned out in the proceedings, the same bags, all originating from Taiwan, were available in a number of other Member States of the (then) EEC, where they were traded freely. Defending itself against NKG's claim, Keurkoop pointed out that instead of rewarding the creation of a design, the right obtained by NKG had the sole purpose of conferring a trade monopoly. This, it was claimed, was incompatible with the principle of free movement of goods, as a prohibitive order against Keurkoop would necessarily extend to items imported from other Member States, where they were freely available. The Gerechtshof Den Haag stated that NKG's registration appeared to be valid, given that Benelux law does not reserve the right to a design to the creator or his successor in title, and also considering that designs are 
deemed as new unless they were known within the Benelux states within the past 50 years. Nevertheless, regarding the points raised by Keurkoop the Gerechtshof saw a need to seek clarification from the CJEU as to the compatibility of Benelux law with Art. 36 TEEC. ${ }^{1}$ As this was the first referral giving the CJEU an opportunity to comment on industrial design rights as potential obstacles to free trade, the case attracted a number of interventions from the Member States. In all of those, it was emphasized that national design legislation at that time was widely disparate and relied on completely diverse concepts. In the opinion submitted by the United Kingdom, it was even held that questions regarding the specificities of industrial design law should not be referred at all to the CJEU, thereby implying that the CJEU had no business to meddle in such purely domestic issues. Though less radical in its abstention, the Court itself formulated a similar view: "in the present state of Community law and in the absence of ... harmonization of laws the determination of the conditions and procedures under which protection of designs is granted is a matter for national rules ... Consequently the rules on the free movement of goods do not constitute an obstacle to the adoption of provisions of the kind contained in the Uniform Benelux Law on Designs."2

In those days, a lack of harmonization of national intellectual property (IP) protection was, of course, the rule rather than the exception. However, industrial design law was different insofar as, in contrast to patent and trade mark law, no efforts had been undertaken to address the issue. True, like patents and trade marks, industrial designs had been placed on the harmonization agenda already when the Common Market was established in 1959, and a report had been delivered to that end by the former president of the Italian Patent Office, Marcello Roscioni. However, while emphasizing the general importance of harmonization in the field of designs, Mr. Roscioni also highlighted the particular difficulties this would imply due to the divergent approaches taken towards protection of shapes in the Member States. It is unclear whether that discouraged substantive moves by the Commission in the field, or whether the issue was rather forgotten. In any case, when eight years after Keurkoop the CJEU had to decide on design protection for spare parts in the light of the competition clauses in primary EEC law, ${ }^{3}$ the

\footnotetext{
1 Now: Art. 36 TFEU.

2 Case C-144/81 Nancy Kean Gifts v. Keurkoop ECLI:EU:C:1982:289, paras 18 and 19.

3 Case C-238/87 Volvo v. Veng ECLI:EU:C:1988:477, para 7; Case C-53/87 CICRA v. Renault, ECLI:EU:C:1988:472.
} 
situation still had not changed - a road map towards harmonization was not even envisaged.

\section{How the Design Proposal Was Launched}

By that time, the situation had become precarious. Politics had set the date for completion of the Internal Market by the end of 1992, and it was obvious that until that time, substantial obstacles to free movement of goods, such as disparate IP protection systems, had to be removed. With the Commission apparently sitting on its hands, academic initiatives rose to the challenge of filling the gap. One of them, consisting inter alia of professors Herman Cohen Jehoram and Marie-Angèle Perot-Morel, held meetings in the north of Italy and became consequently known as the "Treviso Group". Their proposal was to establish an industrial design regime without registration requirements, closely modeled on copyright law, but with a lower threshold for protection and a protection period of 25 years. ${ }^{4}$ It is no secret that this proposal was particularly favored by the textile industry, not least the Italian branch. For other industries, however, the complete renouncement of formalities appeared inept and suspicious, as it would remove the modicum of transparency and legal certainty that a system of design registration, for all its imperfectness, can yield.

This was the state of affairs when the proposal for a "European Design Law" was launched by a working group established in the Max-PlanckInstitute for Foreign and International Patent Copyright and Competition Law (as it then was), consisting of the Institute's director Friedrich-Karl Beier, former president of the German Patent Office, Kurt Haertel, and the authors of this article, Marianne Levin and Annette Kur ("MPI Group"). The declared aim of the proposal was to elaborate a panEuropean concept of design protection, based on a genuine "Design Approach". Thus, instead of proceeding in the usual manner of creating a patchwork from existing rules, the legislation should be founded on autonomous grounds, being informed by the specificities of the subjectmatter rather than by the vagaries of pre-existing legislation in (parts of) the Member States. Like the Treviso Group, the proposal recognized a

4 For details of the proposal see H. Cohen Jehoram, 'Cumulative Design Protection, a System for the EC?', [1989] Eur. Intell. Prop. Rev. 83; see also Camera di Commercio Industria Artigianato Agricolture Treviso (ed.), Disegno Industriale e Protezione Europea (Guiffrè 1989) and the contributions to a symposium held at the University of Grenoble, 'La protection des créations d'esthétique industrielle dans le cadre de la C.E.E.' (Grenoble 1989).

5 MPI Proposal. 
need for informal protection; however, that feature presented a complement rather than the core of the legislation proposed. The rest is history: being invited to discuss the proposal during a scholarly symposium arranged at Ringberg Castle in the Bavarian Alps the Commission representatives warmed to the concept and the text elaborated in the working group, and with few turns and amendments, ${ }^{6}$ the Proposal became the blueprint for the EU design legislation that we know today.

\section{THE DESIGN APPROACH SPECIFIED}

\section{The Previous Situation}

As pointed out above, the conditions under which legal protection could be obtained for the appearance of goods in the Member States of the EEC were quite diverse. On the one hand, this concerned specific industrial design legislation. On the other hand, it applied to the manner in which specific design protection could be complemented on the basis of other legal regimes, in particular by copyright.

The striking diversities characterizing national design legislation and its complements had made the issue an appropriate target for legal research. One of the most comprehensive and in-depth studies had been conducted by Marianne Levin, ${ }^{7}$ who as a member of the MPI Group inspired much of the design proposal's content. In her study, she showed that all of the legislative models she had investigated suffered from one or the other flaw that compromised their efficiency or equitability. The result coincided with empirical evidence established, and legal studies

6 As documented in the various documents and proposals by the Commission, starting with the Green Paper on the Legal Protection of Industrial Design (Working document of the services of the Commission. [1991] III/F/5131/91$\mathrm{EN}$ ), followed by proposals for a Regulation (EC) on the Community Design, COM (93) 342 final, [1993] OJ C 29, 20-49 and for a Design Directive (EC) on the legal protection of designs, COM (93) 344 final, [1994] OJ C 345, 14-18, and finally the amended proposal for a European Parliament and Council directive on the legal protection of designs, final, [1996] OJ C 142, 7-22.

7 M. Levin, Formskydd: En rättsvetenskaplig studie av skyddet för estetiskt syftande industriell formgivning ('Protection of Shape. A legal study of the protection of aesthetically oriented industrial design') (LiberFörlag 1984). See also e.g. M. Levin, 'Der Schutz für Formgebungen', [1985] GRUR Int. 713. 
undertaken, ${ }^{8}$ in the framework of deliberations on a potential revision of the old German Design Protection Act. While they were less comprehensive in coverage, those efforts also indicated a clear mismatch between the goals and the means of design protection.

The choices faced by legislators at that time were usually termed as "patent" and "copyright" approach respectively. By and large every national design legislation was counted in one or the other camp, depending on its characteristic features. In their purest forms, the patent and copyright approaches were represented by Nordic design legislation on the one hand and French law on the other. Like patent law, Nordic law applied a strict novelty criterion without a grace period, relied on substantive examination, and provided protection against all subsequent designs falling into the scope of the prior design, without knowledge of the infringer having to be established. In France, publication of the design by the personal creator or his successor in title was not detrimental to novelty, meaning that it could be registered at any time after publication; no substantive examination was carried out, and protection was granted only against copying. Most other European laws were closer to the Nordic model than the French one, with Germany forming an exception insofar as, there as well, registration of a design only conferred protection against copying. However, different from France, publication by the designer resulted in destruction of novelty, unless it fell within the grace period of six months.

Regarding protection based on other grounds, the focus lay primarily on copyright. In particular France was known for its generous attitude towards copyright protection for works of applied art, based on the concept of "unité de l'art".9 In practice, this led to almost complete cumulation ("cumul total") of design and copyright protection. ${ }^{10}$ In stark

8 See in particular B. Englert, Grundzüge des Rechtsschutzes der industriellen Formgebung (Heymanns 1978) at 181 et seq. (referring inter alia to an extensive survey among entrepreneurs from design-oriented industry sectors).

9 Levin, Formskydd, supra note 7 at 101 et seq.

10 In the Benelux countries, the legal situation had been divided between Belgium - where the French model was followed - and the Netherlands, where a more elevated threshold for protection applied. In order not to disrupt the common approach towards protection of product appearances promulgated in the uniform Benelux design legislation, the latter incorporated a clause according to which copyright could only be granted to useful articles if they were of a markedly artistic character. However, when asked for the interpretation of that clause in a case regarding automobile curtains, the Benelux Court declared that the standards for assessing copyright protection for works of applied arts should not be different from that applying in other fields of the art, thereby establishing 
contrast to the situation in France, Italian law applied the criterion of scindibilità (separability), meaning that similar to US law the appearance of useful articles could only be protected if and to the extent it was possible to separate, at least conceptually, the artistic elements from the functional. ${ }^{11}$ As a practical result, entire product categories such as furniture were effectively barred from copyright protection, irrespective of their artistic merits. In the UK, cumulative protection under copyright and design law was first prohibited; ${ }^{12}$ later on, copyright law restricted protection for articles reproduced industrially ${ }^{13}$ to 25 years from making; further, protection against reproduction of non-artistic drawings in threedimensional form was excluded. ${ }^{14}$ In Germany, legal practice had espoused a middle route based on the so-called theory of tiers, pursuant to which the threshold for copyright protection of useful articles had to be higher than that applied for other categories of art, in order to preserve the "lower tier", and thus a meaningful scope of application, exclusively to design law. ${ }^{15}$ The Nordic countries hovered somewhere between the French and the German positions, with the focus being placed on measuring the scope of protection rather than the threshold.

For the members of the MPI Group it was obvious that the diversities of standards as reflected in national copyright legislations could become a threat to the overall harmonization of IP protection available to product appearances. In the first published version that was discussed inter alia with representatives of the Commission an attempt was therefore made to avoid proliferation of copyright protection by stipulating that a design should only qualify for copyright protection if it displays a higher degree of originality than what is needed to satisfy the corresponding requirement of individual character under design law. ${ }^{16}$ However, any attempt to

a "unite'de l'art" approach, as in France. See Benelux Court of Justice Screenoprint [Automobile Curtain] [1989] IIC, 556.

11 Levin, Formskydd, supra note 7 at 160 et seq.

12 Levin, id. at 130 et seq. and at 144.

13 That is, production of more than 50 copies or by the yard/meter.

14 Sec. 51 and 52 Copyright Design and Patents Act (CDPA) 1988.

15 See German Federal Supreme Court I ZR 119/93, [1997] IIC, 140 (silver brooch representing a thistle, with references to previous case law). In the scholarship the theory was first formulated by E. Ulmer, Urheber- und Verlagsrecht, (1st ed. Springer 1951) at para 25 III 3 (also in the 2nd and 3rd editions, 1960 and 1980).

16 Original wording of the provision (Art. 14): "When products the originality of which exceeds the requirements contained in Article 7 [i.e., novelty and distinctive character, as it was then called] have been protected as Community designs this does not preclude them from being protected as works under 
regulate "through the backdoor" of design protection what actually amounts to the notion of a work was squarely (and correctly) rejected by the Commission staff members. Instead, the MPI Group members put their hopes on the thought that, if properly conceived and constructed, legislation based on the Design Approach would be capable of covering the needs of designers and design-oriented industries to an extent that would render supplementary protection under other legal regimes largely superfluous.

\section{A Market-oriented Perspective}

With the goal being to overcome the schism between patent and copyright approach and to embark on an autonomous route, the MPI Proposal commenced by teasing out the essence of what design protection was actually meant to be. The negative parameters were rather clear: design protection was neither strictly about innovation, nor was it oriented towards furthering individual creativity. Based on the empirical studies that had been conducted before, the starting point was instead located in the manner designs become effective in the marketplace. More specifically, the situation envisaged was that of saturated markets, where demand is no longer driven by the urge to satisfy basic needs, and where the commodities offered are largely interchangeable in their functional aspects. It is then that the design of products becomes a key factor for enabling diversification and reaching out to particular groups of customers. This, in essence, is meant by the term "marketing approach" that was used synonymously with "design approach" in the context of the MPI Proposal as well as in the Commission's Green Paper.

From today's perspective, the concept and the manner in which it was established could be questioned. On the one hand, applying what may be termed a "functional approach" that reflects the operation of specific subject-matter in practice as well as the intentions of those who invest therein certainly has its merits. And of course for us as academics the opportunity to create an entire legal regime that was founded on a concept defined by ourselves was a great opportunity, and we tried to make the best of it, even before it was clear that our proposal would

national copyright law"; MPI Proposal at 21, fn. 13. After the discussions at the Ringberg symposium, the following version of Art. 14 was adopted in the MPI Proposal: "A community design right does not preclude protection of the appearance of the product from being protected as work under national copyright." Thus, different from the wording of Art. 17 DDir Member States were not meant to be obliged to grant such protection. 
actually become the nucleus of European legislation. On the other hand, it is fair to admit that our market-based approach could be criticized as somewhat simplistic and neglectful of potential negative effects on competition and the general welfare. Another point to be mentioned here is that while we considered the risk of overlaps with copyright, the obvious vicinity between our definition of a design's market approach and trade mark law was not clearly articulated, nor were its repercussions analyzed in detail. This is partly due to the fact that the issue has become more pertinent today, as the broader ambit of trade mark functions is more apparent nowadays than at the time of our deliberations. But of course it was clear already then that the market (or design) approach, by distancing itself from patent and copyright law, moved closer to the trade mark law sector in the spectrum of IP protection. Indeed, the market function of a design is, in effect, a kind of communication function. ${ }^{17}$ However, at least in theory a fundamental difference between the two fields of law lies in the fact that the design is not meant to convey any message beyond its own appearance, whereas a trade mark must indicate commercial origin in order to function as such. Expressed in terms of semiotics, the concept of design law implies that the signifier and the signified are collapsed (the product appearance signifies the product appearance), whereas in trade mark law they must be distinct from each other (the product appearance must signify commercial origin). However, in practice the distinction was never easy to draw, and with the concept of trade marks being extended so as to comprise the intrinsic value of brands, the conceptual background as well has become blurred.

\section{Drafting Framework}

The elaboration of the MPI draft occurred at a time when European trade mark legislation was on the brink of being enacted. The Trade Mark Directive (TMD) ${ }^{18}$ became effective in 1989 . The text of the Community Trade Mark Regulation (CTMR) ${ }^{19}$ had equally been finalized at the end

17 See infra, Section II.4(b), item 2 and Chapter 5.

18 First Council Directive (EC) 89/104 to approximate the laws of the Member States relating to trade marks [1989] OJ $L 40,1-7$, now recast as Directive (EU) 2015/2436 of the European Parliament and of the Council to approximate the laws of the Member States relating to trade marks [2015] OJ L $336,1-26$.

19 Council Regulation (EC) 40/94 on the Community trade mark [1994] OJ L 11, 1-36; now recast as Regulation (EU) 2017/1001 on the European Union trade mark (CTMR) [2017] OJ L 154, 1-99. 
of the $1980 \mathrm{~s}^{20}$ and provided a model for our drafting. In addition, inspiration was drawn from the text of the European Patent Convention $(\mathrm{EPC})^{21}$ that had been concluded in 1973. This appeared natural not least because Kurt Haertel was one of the founding fathers of the EPC, and the group thus profited from his drafting experience. In addition, the EPC as well as, to some extent, the Community Patent Convention (CPC), ${ }^{22}$ which never came into force ${ }^{23}$ - had served as models for the CTMR, meaning that acceptability for the European legislature was firmly established in the relevant aspects and thus offered stable ground on which the design proposal as well was able to proceed.

Regarding the format of the proposed legislation, it was considered that the foremost aim should be to create a common right extending throughout the Community, instead of focusing on harmonizing the national laws. Based on previous experience it was even thought that proposing a directive, and thus obliging Member States to change their national law, would raise misgivings and protracted discussions, whereas if legislation were only aimed at the Community level, national politicians would be more likely to leave it to legal experts to regulate the details. Promulgating a directive was also considered unnecessary because of the "cold harmonization" effect that had been observed in the aftermath of the CPC: although it did not oblige Member States to change their patent laws - and even though it never went into force - it had resulted in a large-scale approximation of national laws to the model provided by the proposed Community patent.

For the European Commission, however, that logic was not acceptable. The EEC Treaty made it clear that harmonization directives were the appropriate, if not the only, tool for implementing the goal of the Common Market. This could not be sidestepped in favor of a regulation that was only considered as a supplementary tool for legislation in case

20 The enactment of the CTMR was delayed for another five years due to political quarrels about the working languages and the seat of the Office.

21 Convention on the Grant of European Patents (European Patent Convention) of 5 October 1973, as revised by the Act revising Art. 63 EPC of 17 December 1991 and the Act revising the EPC of 29 November 2000, available at http://www.epo.org/law-practice/legal-texts/html/epc/2016/e/ma1.html (accessed 10 July 2018).

22 Convention for the European Patent for the Common Market (EC) 76/76 (Community Patent Convention) [1976] OJ L 17, 1-28.

23 Though the CPC had been signed by all EEC Member States, the ratification process could not be concluded e.g. in Denmark because of the high hurdles under constitutional law against the delegation of judicial competences to foreign (or international) authorities. 
that important goals could not be achieved by other means. In the subsequent political process, the directive even became the primary focus of legislative attention, due to the fact that, after the Treaty of Maastricht (1993), the European Parliament acquired genuine legislative competences for co-deciding on directives, whereas the Council retained the exclusive power to (unanimously) enact regulations. That made it politically unfeasible to push legislation at the Community level, while a parallel directive was under consideration in the co-decision process.

\section{Salient Features of the Proposal}

\section{(a) Eligibility for protection - definition and exclusions}

As in many other details, the pre-existing legislations differed in regards to the definition of subject-matter qualifying for design protection. For countries following a patent-inspired approach, it appeared natural to confine the protection to the way in which the design manifests itself in a particular article, meaning that protection was necessarily limited to the design as applied to the same product. From a copyright perspective, however, the design was protected "as such", irrespective of the article to which it was applied. The difference becomes topical in the rare cases when a design is applied to products of a different kind (e.g. when the shape of a lock is used for jewelry ${ }^{24}$ and also when three-dimensional designs are reproduced in two-dimensional form. ${ }^{25}$

In the MPI Group, the governing notion was the same as traditionally prevailed in German law, namely that the design was protected as such. It was not deemed necessary, however, to promulgate a legal definition expressly dwelling on that effect, it being understood that doing so might provoke prolonged discussions that could jeopardize the success of the project. Instead it was sought to clarify that in accordance with the underlying concept the notion of protectable designs should be as broad as possible ("the two and/or three-dimensional appearance of products (designs) which is capable of having an effect on the human senses of form and/or colour"). As pointed out in the explanatory memorandum to the MPI Proposal, this definition should comprise all possible elements

24 For an example see also Hoge Raad (Dutch Supreme Court) ECLI: NL:HR:1995:ZC1657: it formed no obstacle to the novelty of a barber's chair for children that the chair was shaped like a Ferrari racing car; see also Green Lane Products Ltd v. PMS International Group plc [2008] EWCA Civ. 358 (massage balls invoked as part of the prior design corpus vis-à-vis a laundry ball).

25 See also infra, Section II.4(f) ("Limitations and exceptions"). 
to be perceived visually, provided they resulted from human activity. It was also emphasized that by using the word "product" instead of "article" it had been intended to indicate that the definition also applied to (detachable) parts of products, instead of requiring that the design object was independently marketable. ${ }^{26}$

While adopting the approach reflected in the MPI draft, the Commission did not accept the premise that the term "product" is selfexplanatory in its breadth and does not need any further definition. Instead, an extra proviso was introduced to ensure a common understanding of the legal ambit of the term, setting forth inter alia that graphical symbols, typographic typefaces and component parts of complex products were meant to constitute potential objects of design protection. That settled any issues regarding the eligibility for protection of the items listed. However, it still left some doubts about the actual breadth of the underlying design concept, which has given rise to uncertainty. For instance, it was not entirely clear from the beginning whether designs used in a different product sector could be invoked as obstacles to protection of a subsequent design, ${ }^{27}$ or whether twodimensional representations of protected shapes would amount to infringement. ${ }^{28}$

As subject-matter to be excluded from protection, the MPI Proposal listed designs that were contrary to public order or morality, as well as designs that were solely dictated by their technical function. The first ground for exclusion was considered as a matter of self-evidence that simply echoed what was also found in the EPC and the CTMR (as it then

26 For the restrictions arguably following from the use of the term "article" see e.g. Sec. 44(1) of the previous version of the UK CDPA, which stipulated that "article" means "any article of manufacture and includes any part of an article if that part is made and sold separately". Based on that definition it was held with regard to spare parts in the House of Lords' decision in Regina $v$. Registered Designs Appeal Tribunal, ex parte Ford Motor Co. Ltd [1994] UKHL 10 (Lord Mustill) that "a spare part has to have an independent life as an article of commerce and not be merely an adjunct of some larger article of which it forms part", and that design protection could therefore not be attained by parts which were merely sold for repair purposes.

27 See the comprehensive discussion of that aspect by Mr. Justice Jacob in Green Lane Products Ltd v. PMS International Group plc [2008] EWCA Civ 358.

28 The issue was only settled recently by a decision of the CJEU concerning representation of Nintendo game consoles in internet advertising for bags fitting (inter alia) those consoles; Case C-24/16 and C-25/16 Nintendo, ECLI:EU: C:2017:724. 
was). Regarding the former, it was emphasized in the explanatory memorandum that the exclusion should be interpreted very narrowly, as a broad exclusion of functional objects "could not be reconciled with the intent and purpose of modern design which lies in the very combination of product aesthetics and optimum functional design". 29 The Proposal thus embraced what is called a "mandatory" approach: "Protection shall only be denied when the accomplishment of the technical function requires a specific form without leaving any scope for variations." 30

The initial drafts presented by the Commission appeared equally strict but were changed in their wording during the negotiations. Following the development in administrative practice ${ }^{31}$ which has now been confirmed by the CJEU in DOCERAM, the mandatory approach can no longer be considered as governing and instead a causative approach must be used. ${ }^{32}$ Furthermore, the provisions finally adopted offer a more detailed form of regulation: instead of excluding functional designs as such, the exclusion only relates to the features that are considered as functional. Also, it is specifically stipulated that the exclusion applies to the so-called "mustfit" features of component parts of complex products that are necessary for the technical transaction of replacement. ${ }^{33}$ Additional complexity was caused by exempting the interfaces of modular products from the exclusion for must-fit parts. That exemption became known as the LEGO-clause - with the LEGO basic brick being the best illustration of designs benefiting from the exemption - and its insertion was frequently, jokingly or not, attributed to the fact that the person responsible for the dossier in the Commission at that time was Danish (as is the LEGO company). However, the reasons underlying the exemption were more substantial than that: it reflects a principle also acknowledged e.g. in German jurisprudence ${ }^{34}$ that allowing replication of the interfaces

\footnotetext{
29 MPI Proposal at 58 (2).

30 Id.

31 See in particular BoA Case R-690/2007-3 Lindner/Franssons (chaff cutter), paras 34 et seq.

32 Case C-395/16 DOCERAM ECLI:EU:C:2018:172. See further Chapter 6.

33 Art. 8(2) CDR; Art. 7(2) DDir. The MPI Proposal had endorsed a similar effect, without articulating it expressly. See at 58 (2.): "These considerations [i.e., exclusion from protection of mandatory technical features] also apply to parts of products such as spare parts for motor vehicles."

34 "Einschieben in fremde Serie"; see German Federal Supreme Court I b ZR 37/62, [1964] GRUR, 621; German Federal Supreme Court I ZR 163/90, [1992] GRUR, 619; and German Federal Supreme Court I ZR 30/02, [2005] GRUR, 349 all concerning the Lego building block, with only the last decision declaring that protection must end after so many years of market exclusivity.
} 
connecting modular products would not just give access to the secondary market of spare parts and accessories, but could be tantamount to appropriating the entire market for the relevant products.

Lastly, the Commission introduced another exclusion by stipulating that computer programs do not qualify as "products" in the meaning of the general definition. This has raised questions as to whether icons and other elements of the graphical user interface must remain excluded from protection, based on the argument that they are generated by software and thus constitute the "appearance" of a "non-product". 35 However, it was clarified early on that such effects were not intended. ${ }^{36}$ As graphical symbols are expressly meant to be products the appearance of which can be protected as a design, such exclusion would not have made much sense anyhow. What the Commission intended by that exclusion was only to ensure that protection of the underlying software could not be claimed on the basis of the "look-and-feel" elements appearing on the screen. ${ }^{37}$ It was feared at the time, that such indirect protection might disrupt the delicate balance found in the newly enacted directive on copyright protection of computer programs. However, those fears appeared somewhat far-fetched even back then, and they are incomprehensible to-date, as it has been stated by the CJEU with desirable clarity that protection of software on the one hand and the graphical user interface on the other are subject to strictly separate appraisals. ${ }^{38}$

35 For the background of the provision and the legal situation preceding the harmonization of design law see A. Kur, 'Protection of Graphical User Interfaces Under European Design Legislation', [2003] IIC, 50.

36 See the explanatory memorandum to the 1993 proposal for a Council Regulation on the Legal Protection of Design (III/F/5576/92-EN). In respect of the provision excluding computer programs from the notion of a "product" in the meaning of the Regulation (corresponding to Art. $1 \mathrm{~b}$ of the current Directive), the explanatory memorandum states on page 9: "As far as computer programs are concerned the exclusion may appear to be superfluous since computer programs as defined in the directive on protection for computer programs (Council Directive (EC) 91/250 on the legal protection of computer programs [1991] OJ L 122, 42-46) cannot be designed. It may be useful, however, to state explicitly that the copyright protection provided under the umbrella of the aforementioned Directive cannot be supplemented or reinforced by a protection of the 'look and feel' of a computer program by way of design protection. This does not exclude the protection of specific graphic designs as applied for example to icons or menus provided the normal requirements for protection are met."

37 See the reasons stated in the explanatory memorandum to the 1993 Commission proposal, id.

38 Case C-393/09 BSA v. ministry of culture [2010] ECLI:EU:2010:816: “A graphic user interface is not a form of expression of a computer program within 


\section{(b) Protection requirements}

1. Prior disclosures: As pointed out before, the Proposal elaborated on the basis of the Design Approach was meant to avoid flaws identified in the pre-existing systems. Of primary concern in that regard was the concept of novelty, more specifically: of prior disclosure. From the market-oriented perspective espoused by the MPI Group, it was neither necessary nor appropriate to require that the design be novel in the meaning of "previously unseen". A strict novelty requirement in that regard could only be justified by the thought that when an invention has been disclosed, there is no need to "reward" the inventor for filing the patent. However, that thought is moot anyhow for designs that have nothing to disclose but themselves. Furthermore, the empirical research undertaken in the studies preceding the MPI Proposal ${ }^{39}$ had shown that a strict novelty requirement operated to the detriment in particular of individual designers who were badly informed about the legal requirements and who, in their eagerness to share with the world the results of their efforts, by early publication tended to destroy their options for subsequent protection. ${ }^{40}$ From this came the idea to grant an extended grace period of one year, to avoid loss of rights by inadvertence, and to provide an opportunity to test the marketability of new designs under "real life"-conditions before deciding whether to opt for full term protection. ${ }^{41}$

the meaning of Art. 1(2) of Council Directive 91/250/EEC of 14 May 1991 on the legal protection of computer programs and cannot be protected by copyright as a computer program under that directive. Nevertheless, such an interface can be protected by copyright as a work by Directive 2001/29/EC of the European Parliament and of the Council of 22 May 2001 on the harmonisation of certain aspects of copyright and related rights in the information society if that interface is its author's own intellectual creation" (operative part of the judgment, no. 1).

39 In particular the survey reported in the book by Englert, supra note 8; Another study had been undertaken by the ifo-Institute (Leibniz Institute for Economic Research at the University of Munich) in the years 1980-1981.

40 Levin, Formskydd, supra note 7 at 342 et seq. See also M. Levin, 'Die Zukunft des Designschutzes in Europa aus der Sicht der nordischen Staaten', [1998] GRUR Int. 371 at 371.

41 For a detailed motivation pointing to the needs in particular of small and medium-sized enterprises (SMEs) and individual designers see MPI Proposal at 49 (explaining why a patent law-type of novelty requirement was considered inappropriate). 
Of course, it was also realized that granting such a long grace period could have its pitfalls, as it might trigger mistaken beliefs that other countries or regions are equally generous. Also, while designs are used on the market without being backed by a registration, they are not safe against others independently developing the same or a similar design. This will destroy novelty, as the grace period can only be relied upon if the designer her-/himself or her/his successor in title, or someone copying from her/him, has published the design during the 12 months preceding the application date; independent publications by third parties are, and remain to be, novelty-destructive. However, the advantages for the designer of preserving a meaningful time of market-testing were considered as overriding the potential drawbacks.

2. Qualitative step: In addition to a design appearing as novel in the sense that the same or a quasi-identical configuration was not published before, it is necessary that the design is also new in a qualitative sense, i.e. that it differs from the existing design corpus. In practice, that qualitative step is regularly more important - and contentious - than ascertaining novelty in the narrow sense. On the basis of the Design Approach, this means in essence that the design must be capable to communicate, not in the meaning of trade mark law by conveying a message about commercial origin, but by presenting itself as something special, capable of attracting the attention of customers on markets where functional properties no longer account for crucial distinctions. Keeping a certain distance from others was therefore all that should be required.

By espousing that concept, alternative notions frequently found in pre-existing design legislation were implicitly discarded. Thus, no heed should be given to the aspect of whether the design was "aesthetically appealing" - the aesthetic quality of the design should only be for the public to judge and to react to; the law had to remain neutral in that regard. By renouncing the criterion of aesthetic effect the proposal was inherently extended to cover also product appearances that were of a primarily functional nature. As was pointed out above, ${ }^{42}$ exclusion from protection for reasons of functionality was only considered as necessary where a shape was entirely dictated by its technical purpose - it being understood that the Design Approach commanded a narrow application of that exclusion.

\footnotetext{
42 Supra, Section II.4(a).
} 
Second, under the Design Approach it was considered crucial that the granting of a design right should not be made dependent on the achievement surpassing the skills of an ordinary designer. ${ }^{43}$ Again, that notion appeared to be a standard erroneously adapted from patent law, where the inventive step must be exceeding the normal contribution of a person having ordinary skills in the art. In the case of designs, it is neither the level of inventiveness nor of creativity that counts: the spotlight is not on the designer and her/his skills, but rather on the product itself and the reaction it is able to evoke from the public. Based on that consideration, it was postulated that the assessment should proceed from the perspective of "the market", i.e. the target group envisaged by the designer. ${ }^{44}$ With German being the working language within the group, it was decided that the German term Eigenart was best suited to express the concept (in contrast to the term Eigentümlichkeit then used in the German design legislation, which had a strong affinity to "originality" in copyright). Somewhat unfortunately, the term was translated as "distinctiveness" in the English version of the draft, which over-emphasized the proximity to trade mark law.

While the basic concept espoused by the MPI Proposal is still recognizable in the current legislation, a number of changes were put in place. The first one was only of a linguistic nature, exchanging "distinctiveness" for "individual character" (with the German terminology remaining unchanged). More importantly, during the legislative process the proposition to let the "market" decide whether a design could be protected (or was infringed) met with criticism from two opposite sides: on the one hand, it was feared that in order to establish protectability (or infringement) of a design, it might become necessary to conduct market surveys that would make the proceedings overly costly and cumbersome. From

43 See MPI Proposal at 60/61 (comments on the requirement of what was then called "distinctive character"): "eligibility for protection does not depend on a quality test, which would require the design effort to be above the skill of an ordinary designer ... what is required is only a sufficient degree of differentiation, so that the design may be appreciated as having a 'character of its own'. This requirement may even be satisfied by a rather small degree of differentiation, where the overall appearance is changed so that it bears a special, distinguishable 'stamp'."

44 See MPI Proposal at 48: "Industrial creation is normally created in order to promote sales ... It is the market which determines what designs are new and original." 
a different angle, it was argued that relying on the perception of the relevant public would make it impossible to introduce testimonies of design experts, which might be needed in particular in cases where the available space for a designer is relatively narrow: only the educated eye would, in such situations, be able to see and explain the differences, while the "woman or man in the street" would see one and the same design. If strictly implemented, a market approach would therefore lead to discouragement of incremental design creations in crowded areas.

In response to both types of criticism the notion of "informed user" was developed in subsequent Commission proposals. This was meant to express, first, the normative nature of the standard to be applied, meaning that no resort must (and should) be taken to consumer surveys. Second, by switching from a "simple" to an "informed" market perspective it is possible to adduce evidence of what the expert eye is more likely to detect than an ordinary consumer. Basically, the same principle is embedded in the proviso that regard must be given to the freedom of the designer - there as well, the intention is to allow for protection being granted in spite of the parameters for creation being narrowly framed. As was aptly pointed out in several decisions by the European Courts the "informed user" is supposed to keep equidistance between the ordinary consumer of trade mark law and an expert in the field, ${ }^{45}$ such as the person having ordinary skill in the art in patent law. While that is clear and plausible in theory, it remains a somewhat challenging task for practice to keep the different standards apart.

3. Range and threshold of assessment: Apart from defining the reference person, two other elements of the assessment had to be specified: first, the territorial and/or temporal dimensions of the relevant corpus of prior designs, and, second, the distance to be kept from pre-existing designs in order to qualify for protection. Regarding the first of those aspects - the determination of the relevant design corpus - some of the previous design laws required absolute, world-wide novelty like in patent law, whereas others

45 See in particular Case C-281/10 P PepsiCo v. Grupo Promer Mon Graphic ECLI:EU:C:2011:679, para 53: "that concept must be understood as lying somewhere between that of the average consumer, applicable in trade mark matters, who need not have any specific knowledge and who, as a rule, makes no direct comparison between the trade marks in conflict, and the sectoral expert, who is an expert with detailed technical expertise." See also further references to jurisprudence in Chapter 3, Section II.4 and II.7. 
applied various kinds of limitations. For instance, the Benelux system (as reflected in the Keurkoop decision ${ }^{46}$ ), applied a notion of novelty that was limited both in regards to time (50 years before the filing date of a design) and territory (only designs that were known in the Benelux states). Reaching somewhat beyond that, in Germany the relevant design corpus was considered to comprise what was, or could have become, known to designers operating within the German territory. ${ }^{47}$

A similar approach was also adopted in the MPI Proposal, based on the consideration that requiring absolute novelty was inappropriate for the field. ${ }^{48}$ By contrast to patent law, documentation of prior designs is lacking or incomplete. Furthermore, different from technical innovation, creation of designs does not progress in a linear fashion but is rather subject to cyclical movements, with old styles being re-discovered and adapted to contemporary tastes. For the same reasons, it was held that the threshold, i.e. the distance between what was protectable under the proposed concept and pre-existing designs, should not be too high, exactly because also mere "recycling" of designs, if done in a manner that gave the design its own communicative character (in the sense explained above), should qualify for protection. ${ }^{49}$

Again, the proposal made by the MPI Group was accepted in principle but modified in detail during the subsequent deliberations. The notion that only such prior designs should pose an obstacle to protection that were, or should be, known to European designers was attacked as being inappropriately Europe-centered, which was not only outdated in the time of globalization, but could also be seen as an incentive to "steal" designs in non-European countries, in particular the developing world. In reaction to the criticism the Commission in their subsequent proposal switched to requesting absolute novelty. ${ }^{50}$ However, that again led to criticism, this time motivated by fears that it would make it easy for infringers to fake evidence that the same or a similar design had been seen before in some remote part of the world. The Commission finally settled on

\footnotetext{
46 Supra note 2.

47 Following the decision by the German Federal Court of Justice I ZR 67/65 Rüschenhaube (bonnet with ruches), [1969] GRUR, 90.

48 MPI Proposal at 49.

49 MPI Proposal at 51 and 61, with specific reference being made to the fashion industry.

50 In the proposals of 1993, supra note 6.
} 
the compromise solution reflected in Art. 7(1) CDR: while absolute novelty is the rule and evidence produced of pre-existing designs may therefore lead to invalidation, the proprietor of the design can counter such allegations by establishing that the publication of the design could not be known to the circles operating in the EU in the sector concerned. While that comes close to the original proposal made by the MPI Group, it is different insofar as it is the designer, and not the person attacking the validity of the design, who carries the burden of proof.

Some back-and-forth movement also characterized the discussions regarding the relevant threshold. ${ }^{51}$ The different positions taken by the Commission in the course of those deliberations reflected, on the one hand, the wish to create a "strong" right, which appeared to require a sufficiently substantial threshold; 52 however, on the other hand the intention also was to provide for a broad coverage of design-oriented industries, and especially the representatives for the textile industry left no doubt that they would find anything but a minimal threshold unacceptable. The latter concerns ultimately proved to be more relevant; therefore, the legal text does not indicate any qualification of the difference that must exist between the design seeking protection and the prior art. However, a trace of the preceding discussions is still found in the

51 The 1993 proposal, supra note 6, required that for establishing individual character, designs must "significantly" differ from the relevant design corpus. In order not to make it too difficult to attain that threshold, Art. 6(2) in the 1993 proposal confined the relevant prior art to designs that at the relevant (priority) date were commercialized on the market, or had been published subsequent to a design registration that was still in force. During the subsequent negotiations, the European Parliament requested that the word "significantly" should be deleted. The Commission concluded that the deletion of the qualifying element made any restrictions of the relevant prior art superfluous, so that the standards for determining the relevant design corpus for assessing novelty and individual character could be aligned. See amended Commission proposal of 1996, supra note 6. Explanatory Memorandum at 3 and 6. See also infra, note 53, for subsequent changes in the preamble.

52 This was of interest not least in the context of discussions regarding the spare parts issue: Initially the Commission tried to soothe concerns of independent manufacturers of such parts by emphasizing that design protection of parts was highly unlikely in view of the substantial threshold required. 
preamble where it is pointed out that the designs must "clearly differ" from each other. ${ }^{53}$

\section{(c) Unregistered designs}

The most innovative feature of the MPI Proposal ${ }^{54}$ was presented by the "two tier"-kind of protection offered: besides the traditional, established route of registration, protection against imitation should also be obtainable for a short period without any formalities. That such short-term, informal protection would offer an appropriate remedy against manifest shortcomings of the current systems had been one of the crucial findings in Marianne Levin's doctoral thesis: in particular in the fashion industry, copying was claimed to be a rampant problem. On the other hand, in view of the short life-cycle of the products, any form of short-lived design registration was considered too cumbersome and costly to offer genuine relief. From the perspective of the other group members, the idea of granting informal protection fitted nicely with a line of jurisprudence that had been developed in German jurisprudence on the basis of Unfair Competition Law, pursuant to which protection for two consecutive seasons was granted against imitation of fashion articles owning some degree of "competitive individuality" (wettbewerbliche Eigenart). ${ }^{55}$ It

53 In the Commission proposal of 1996, supra note 6, the preamble was silent about the threshold. However, based inter alia on interventions by the Nordic States, Recital 13 stating that individual character will only be found if the design "clearly differs" from the relevant prior art was inserted as a result of negotiations leading to the Common position adopted by the Council on 17 June 1997, [1997] SEC (97) 1107 final. The resulting discrepancy between the wording of the preamble and the legal text was (mis)understood by Lord Justice Jacob as indicating that while the threshold for attaining protection must be high (i.e. the design must be significantly different from the existing design corpus), infringement should already be denied if the allegedly infringing design was "different", without any qualification; see Court of Appeal for England and Wales, Procter \& Gamble Co v. Reckitt Benckiser (UK) Ltd [2007] EWCA Civ 936.

54 It has correctly been claimed that neither the MPI Proposal nor the Commission have actually "invented" unregistered design protection, but that this already existed in UK legislation (Bill Cornish in an editorial in [1991] Eur. Intell. Prop. Rev. at 3-4). On the other hand, the UK unregistered design had different objectives and was based on a different concept. It rather appeared to make up for the lack of unfair competition protection against imitation rather than integrating informal protection into the framework of design legislation.

55 German Federal Supreme Court 1 ZR 39/71 (KG) Modeneuheit (fashion novelty), [1973] GRUR, 478; German Federal Supreme Court I ZR 158/81, [1984] IIC, 777 Hemdblusenkleid (shirt dress); German Federal Supreme Court I 
was an easy conceptual step from there to transpose that kind of protection into the overall structure of design law.

It was understood within the MPI Group that the prerequisites for protection should be the same for "ordinary", registered designs and those protected only informally. That way, the proposal distinguished itself from the already existing British variety of unregistered design protection that relied on different protection criteria and was meant to cover different - more functional - articles than those that were typically eligible for registered design protection. Regarding scope of protection, initially the intention had been to grant protection only against identical or very close copying. Those ideas were abandoned before final publication of the proposal in favor of a uniform concept of scope (see also below). However, it was still emphasized that protection would in all likelihood be confined to close imitations because only then would it be unproblematic in practice to prove copying.

Regarding duration of unregistered design protection there was general consent that the period should be long enough for recoupment of investments into the creation of typically short-lived products, whereas it should be appreciably shorter than what could be obtained through registration. ${ }^{56}$ An adequate means between those two goals was found by doubling the length of the protection period available at that time under the German "fashion novelty" concept (two consecutive seasons), i.e. two years.

The Commission readily adopted the concept. While keeping the general features proposed, the duration of informal protection was prolonged by one year.

\section{(d) Scope (including duration) of protection}

One characteristic dividing line separating systems following a patent approach from those applying a copyright approach runs between protection against copying and protection with a barring effect. Only the first approach requires knowledge of the infringer, whereas the second is only based on priority and an objective assessment of identity or similarity. In the MPI Proposal, that distinction was applied to unregistered versus

ZR 286/89 Kastanienmuster (chestnut pattern), [1991] GRUR, 914; German Federal Supreme Court I ZR 113/90 Pullovermuster (patterned sweater), [1992] GRUR, 448; German Federal Supreme Court I ZR 102/95, Trachtenjanker (Bavarian jacket), [1997] GRUR, 477.

56 This marked another distinction vis-à-vis the UK unregistered design, which runs up to 15 years, with the last five years being subject to licenses of right. 
registered design: for the former, it was considered as following from general considerations of equity that protection could only be granted against copying. Regarding registered designs, however, the second, patent-type approach imposed itself as the most suitable solution. Not only did that comply with the large majority of Member States' jurisdictions, thus triggering broad acceptance. It also appeared as an appropriate scheme in the light of the Design Approach, considering that once a prior design has made for its specific place in the spectrum of available alternatives, the marketing opportunities thus established should not be distorted by a later-comer, irrespective of whether the design had been created independently or by imitating. In the explanatory memorandum, yet another reason is given, namely that granting protection without the need for showing copying offers an (additional) incentive for registration. ${ }^{57}$

The same incentivizing effect was also ascribed to the (much) longer duration of registered design protection that was proposed to last for five years with subsequent prolongation adding up to a total of 25 years. That maximum term was chosen, first, because it appeared to strike a compromise between the shorter life-span that the legislation in most Member States granted at that time to industrial designs and the indeterminate duration of protection granted under Portuguese law. Another and arguably more important reason was derived from the consideration that 25 years was the minimum time of protection that the Berne Convention accorded to works of applied art. By equaling the terms it should be signaled to the Member States applying a very generous attitude towards copyright protection of useful articles that if protection of such items became reserved for design legislation, substantive compatibility with the Berne Convention still would be maintained to the best possible extent. ${ }^{58}$

Another question to be answered in terms of scope concerned the relationship between the prerequisites and the extent of protection. Should they be the same, or should one exceed the other? For instance, in patent and copyright law, the scope of protection can surpass what is needed for acquisition of such rights; thus, patentable inventions may fall into the ambit of an earlier patent, and adaptions and translations of works are themselves protectable under copyright. Though being protectable as such, the exercise or exploitation of such rights is contingent upon the consent of the proprietor of the earlier right. Whether or not a

57 MPI Proposal at 65.

58 See the motivation given for the 25-year term in the MPI Proposal at 64 . 
similar scheme should also apply to designs was discussed in the MPI Group, with the opinion prevailing that this would render the system too complicated, as it might call for establishing specific mechanisms, such as granting of compulsory licenses, in the case that consent to the exercise of dependent design rights was denied. However, the wording chosen in the MPI Proposal still appears to indicate that whereas basically any difference vis-à-vis pre-published designs is sufficient to acquire a right, the existence of such differences does not necessarily mean that prior rights are not infringed, given that pursuant to Art. 13(2) of the MPI Proposal "correspondence of overall impression", and thus infringement, can be found where the appearances do not differ "substantially". 59 The possibility that designs displaying the modicum of difference vis-à-vis existing designs that usually qualify for protection may not be sufficient to escape infringement is also mirrored in Art. 13(3) of the Proposal pursuant to which the scope of protection should be measured according to the "degree of distinctive character" of the prior design. As is set forth in the explanatory memorandum, the purpose of that clause is to ensure, on the one hand, that "small coin", or designs that are largely functional, only receive a narrow scope of protection. On the other hand, however, it shall also be observed that highly distinctive design gets a larger scope of protection, which may eventually comprise designs that, as such, might be found protectable. ${ }^{60}$

The Commission's proposal resulting in current design legislation chose a different approach. By using the same wording for measuring the prerequisites and the scope of protection, it is made clear that both are the same, i.e. a design cannot fulfill the prerequisites for protection and still be infringing, or, vice versa, designs that infringe a prior design are per se unable to satisfy the protection requirements ${ }^{61}$ (principle of reciprocity). That approach as well raises certain issues: in particular, it is unclear whether it means that the scope of protection once acquired

59 Cf. MPI Proposal at 20 (Art. 13(2)). In the original version, the provision had added a second sentence, stipulating, "In this respect, common features shall be given more weight than differences." The sentence was deleted, as it was held in the discussions that it would inappropriately limit judicial freedom.

60 MPI Proposal at 65(3.).

61 This is only different in case that the prior design was not (yet) published. In that situation the design can only be invalidated on the ground that it conflicts with a prior right, and not because it lacks novelty or individual character. However, that does not disprove the principle formulated in the text above, because, had the design been published before, the assessment of the protection requirements would necessarily lead to a negative result. 
remains fixed throughout the design's lifetime or whether designs that are far advanced at the time of development can "dwindle" over time, as others try to follow - though with some distance - the trend established by the first comer, making the design look increasingly common over time. ${ }^{62}$

\section{(e) Procedures}

Concerning procedures, the fundamental decision to be made is whether to conduct substantive examination or to carry out an only formal exam. While it is true that rights granted after substantive examination are more secure, and therefore stronger in principle, the specificities of design render that principle doubtful. Unlike patent law, there is no reliable documentation of the existing design corpus, due to the fact that designs are not as regularly filed for registration as one can expect with regard to inventions (at least those which are not kept secret, and which are therefore liable to destroy novelty). Thus, claims are precarious that an examination taking account of (domestic) design registrations and applications is able to substantially improve legal certainty. If a design is subsequently attacked, it will frequently prove highly vulnerable when references are adduced to prior designs used on the market. On the other hand, conducting a more comprehensive examination that includes unregistered prior art would require enormous efforts translating into prolonged procedures and skyrocketing filing costs, which would squarely contradict the interest of users. For those reasons, it was decided that the examination should be restricted to formalities as well as to issues of eligibility for protection. Furthermore, in order to keep the proceedings short and efficient, no opposition was catered for. ${ }^{63}$ Objections against protection should only be articulated in the form of requests for cancellation at the Office or, following the pattern set forth in the CTMR, as counterclaims in infringement proceedings.

In those aspects, the proposal was adopted without major changes by the Commission. However, whereas the MPI Proposal included an optional system of searches, this was not included in the Commission proposals. Accepted, but subject to changes, were also the proposals for deferred publication and multiple applications. In the latter aspects the details of European design legislation were further influenced by the efforts undertaken within WIPO to reform the system of international

\footnotetext{
62 Further on this aspect see Chapter 8.

63 MPI Proposal at 55.
} 
deposit of industrial designs that resulted in the adoption of the Geneva Act of the Hague Convention. ${ }^{64}$

\section{(f) Limitations and exceptions}

Trying to be "modern" in its ambition and attitude, the MPI Proposal is a genuine product of its time, when the approach towards IP protection was strongly affirmative on the political as well as on the scholarly level. A token of that attitude is the fact that the proposal was strongly focused on the presumed interests of designers and the relevant industries, while not much attention was paid to limitations and exceptions. The relevant provision in the MPI Proposal (Art. 23) only lists non-commercial use as well as limitations in view of vessels or aircraft in transit that are mandatory under Article $5^{\text {ter }}$ of the Paris Convention and the Chicago Convention on air traffic. It is true that prior users' rights as well are included in the Proposal, ${ }^{65}$ as the MPI Group considered them as a necessary corollary to the objective, priority-based kind of protection conferred through registration. ${ }^{66}$ However, it was not realized that, when designs are protected "as such", including representations in other (two-dimensional) forms and for purposes other than being applied to an article, ${ }^{67}$ a broader notion should also have governed the limitations and exceptions, in order to encompass the kind of conflicts that such uses might produce. 68

The Commission proposal went somewhat further in the right direction, by adding citation and use for teaching and illustration. However, that enlarged catalogue is also quite narrow and does not provide clear guidelines in a number of situations that were not considered by the historical lawmaker. For instance, it is somewhat incomprehensible that

64 Hague Agreement Concerning the International Registration of Industrial Designs, Geneva Act [1999] (entry into force: 23 December 2003), text available at http://www.wipo.int/wipolex/en/details.jsp?id=12531 (accessed 10 July 2018).

65 Art. 26 of the MPI Proposal.

66 MPI Proposal at 68/69.

67 As explained supra Section II.4.(a), while this point was not explicitly addressed in the proposal, this was the majority understanding in the MPI Group, based on the attitude traditionally governing in German law.

68 Inter alia this concerns the notion of "citations". In order to make sense in the design context it cannot be interpreted in the same manner as in copyright (see, however, BGH I ZR 56/09 (KG) ICE, [2011] GRUR, 1117). The interpretation must rather rely on a comprehensive assessment of, whether in the light of the interests involved, displaying the design for illustration purposes complies with "honest practices". See Case C-24/16 and C-25/16 Nintendo, supra note 28. 
the catalogue of limitations is narrower than in copyright, even though certain copyright limitations could also become relevant in a design context. It is submitted that such discrepancies were not intended; this is rather a case of inadvertence. Regarding prior users' rights, a pertinent provision was inserted in the Community Design Regulation, while it was left for the Member States to regulate that notoriously contentious issue according to their own preferences.

Another issue to which the MPI Proposal did not pay much attention is the protection of spare parts. It was expected that the solution for problems arising in that context would follow from the exclusion from protection of designs that are solely dictated by their function. ${ }^{69}$ In the preliminary draft directive published together with the Green Paper on the Legal Protection of Industrial Designs (1991) ${ }^{70}$ basically the same approach was adopted; only it was clad in the express exclusion of "must-fit" elements. This provoked criticism, both from car manufacturers who felt that even that curtailment of protection went too far, and also from the spare parts industry. Only then the entire dimensions of the issue became visible. Neither for us, nor for the Commission was it conceivable in the early days that this particular issue would become the main obstacle for speedy enactment of European design legislation, and that it would linger on, unsolved, about 15 years thereafter. ${ }^{71}$

\section{CONCLUSION AND PREVIEW - ISSUES TO DISCUSS}

Looking back, the elaboration of the design proposal appears like a lucky moment in time that could hardly present itself in a similar way under contemporary circumstances. For the Commission, it would be unthinkable nowadays to adopt, nearly tel-quel, a piece of legislation formulated by an academic group that was not even officially endowed with that task. It helped of course that our approach was decidedly pragmatic and basically positive towards the grant of exclusive rights, with the axiom that the kind and extent of protection should be governed by the "marketing effect" of designs being fully embraced instead of being set out for the fundamental criticism that today's more skeptical generation of scholars might be ready to engage in.

\footnotetext{
69 MPI Proposal at 58(2.).

70 Green Paper on the Legal Protection of the Industrial Design, supra note 6.

71 See further on this in Chapter 6.
} 
Be that as it may, it remains remarkable that current European design law is among the few pieces of EU legislation that can be traced back to a coherent, autonomous concept developed by a group of scholars. This makes it worthwhile to investigate to what extent the concept is reflected in today's practice. Was it possible for design rights to claim their genuine place in the universe of IP, and is the law applied in a manner that reflects the original ambitions and intentions? We will come back to this question in the concluding chapter of this volume. 